\title{
Notes on the egg of Scopura longa Uéno (Plecoptera)
}

\author{
T. Kawai? \\ Y. Isobe 1
}

The egg of $S$. longa is described and illustrated (SEM micrographs).

Notes sur l'ceuf de Scopura longa Uéno (Plecoptera).

Description et photographies en microscope à balayage de l'œuf de $S$. longa.

The family Scopuridae is a unique family in the Plecoptera of the northern Hemisphere. Its distri. bution seems to be restricted to the middle and northern parts of the Japanese Islands and to the peninsula of Korea. We have no records from other regions of the world.

The family consists of two species, Scopura longa Uéno, 1929 and S. prolifera Kawai, 1974. It is possible to identify specifically only the male specimens : the identification of other forms, female and nymph, is impossible, because we could not find any morphological differences between the species.

As far as it is known, nearly 400 localities have been recorded from Hokkaido, Honshu and Korea.

1. Biological Institute, Nara Women's University. Kitauoya nishi-machi, Nara, 630 Japan.
But most of those are records for nymphs. The distribution records of the imagines of the two species consist in 25 localities from Honshu (main island of Japanese Islands). It is very difficult to obtain the imaginal specimens. As stated above, it was impossible to obtain the female and nymph of $S$. prolifera.

We report the morphological features of $S$. longa egg. Nobady reported on the microstructure of the egg. The material was obtained from a female collected in Mt. Hachibuse, Shinano, in middle Japan. It was certainly S. longa. The egg was gold coated at $5 \mathrm{~mA}$ for two minutes and observed by a scanning electronmicroscope.

The egg is short, ovate, $300 \times 250 \mu \mathrm{m}$. The surface is not very hard, is covered with a fine membrane and lacks a collar and other particular structures. The surface of the fine membrane is rasp-like and scattered with many filiform processes 2.5 $3 \mu \mathrm{m}$ long at a density of 5-7 processes per $50 \times$ $50 \mu \mathrm{m}$. The micropyles were not found anywhere on the egg surface.

\section{Article available at http://www.limnology-journal.org} or http://dx.doi.org/10.1051/limn/1984020 

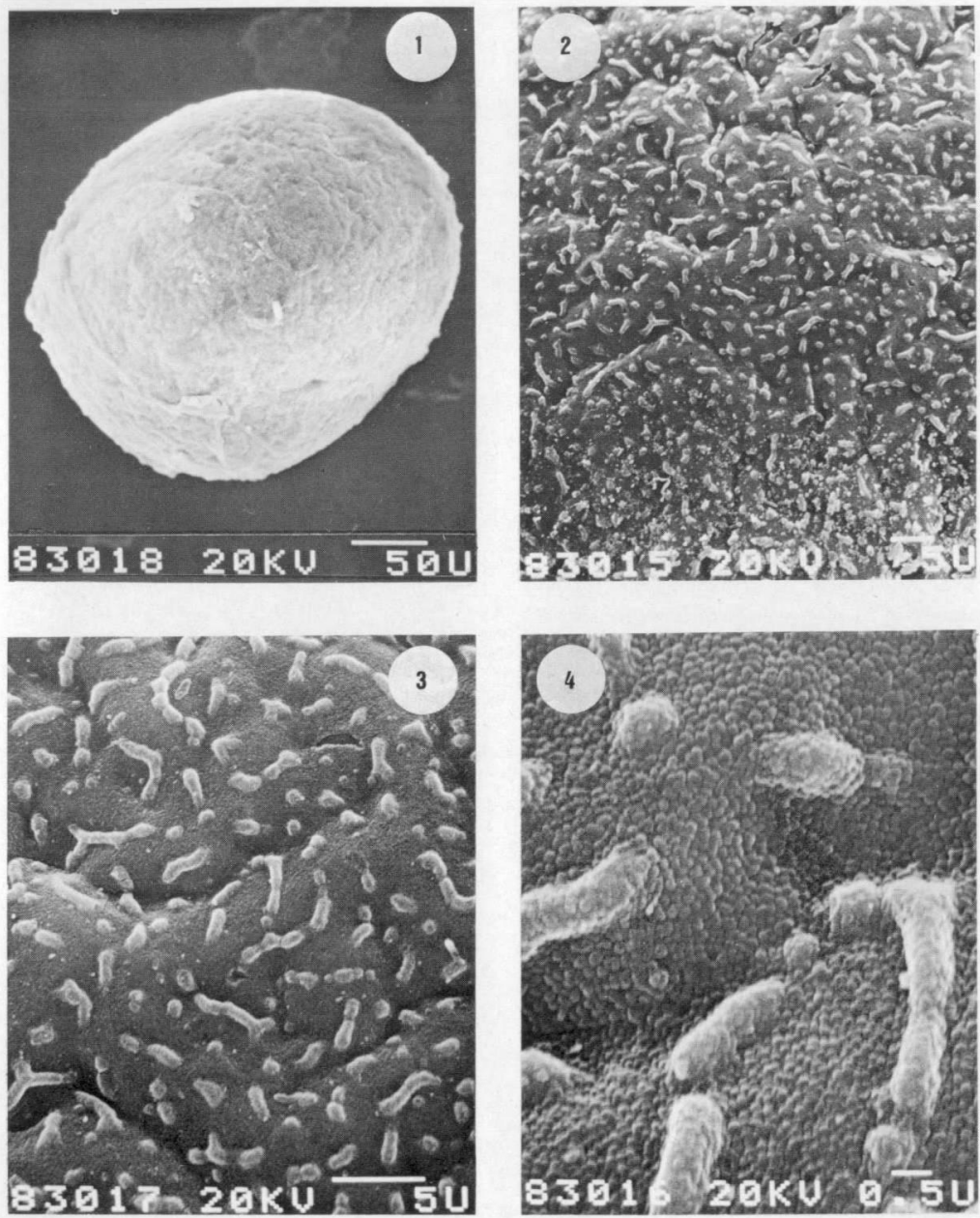

Fig. 14. Scopura longa, SEM micrographs of egg; 1 , whole egg, $176 \times 2$, details of chorion, $882 x ; 3$, id., $2206 \mathrm{x}$ : 4, filiform processes $8823 x$. 